\title{
AMPK: a master energy regulator for gonadal function
}

\author{
Michael J. Bertoldo ${ }^{1}$, Melanie Faure ${ }^{2}$, Joëlle Dupont ${ }^{2}$ and Pascal Froment ${ }^{2 *}$ \\ 'Discipline of Obstetrics and Gynaecology, School of Women's and Children's Health, University of New South Wales, \\ Sydney, NSW, Australia, ${ }^{2}$ Unité de Physiologie de la Reproduction et des Comportements, Institut National de la Recherche \\ Agronomique, UMR85, Nouzilly, France
}

\section{OPEN ACCESS}

Edited by:

Hubert Vaudry,

University of Rouen, France

Reviewed by:

Luis J. Garcia-Marin,

University of Extremadura, Spain

Maria Fernanda Riera,

Centro de Investigaciones

Endocrinologicas-CONICET-GCBA,

Argentina

*Correspondence:

Pascal Froment

Unité de Physiologie de la

Reproduction et des Comportements, Institut National de la Recherche

Agronomique, UMR85,

37380 Nouzilly, France

pascal.froment@tours.inra.fr

Specialty section:

This article was submitted to Neuroendocrine Science,

a section of the journal

Frontiers in Neuroscience

Received: 09 March 2015

Accepted: 19 June 2015

Published: 14 July 2015

Citation:

Bertoldo MJ, Faure M, Dupont J and

Froment $P$ (2015) AMPK: a master

energy regulator for gonadal function.

Front. Neurosci. 9:235.

doi: 10.3389/fnins.2015.00235
From C. elegans to mammals (including humans), nutrition and energy metabolism significantly influence reproduction. At the cellular level, some detectors of energy status indicate whether energy reserves are abundant (obesity), or poor (diet restriction). One of these detectors is AMPK ( $5^{\prime}$ AMP-activated protein kinase), a protein kinase activated by ATP deficiency but also by several natural substances such as polyphenols or synthetic molecules like metformin, used in the treatment of insulin resistance. AMPK is expressed in muscle and liver, but also in the ovary and testis. This review focuses on the main effects of AMPK identified in gonadal cells. We describe the role of AMPK in gonadal steroidogenesis, in proliferation and survival of somatic gonadal cells and in the maturation of oocytes or spermatozoa. We discuss also the role of AMPK in germ and somatic cell interactions within the cumulus-oocyte complex and in the blood testis barrier. Finally, the interface in the gonad between AMPK and modification of metabolism is reported and discussion about the role of AMPK on fertility, in regards to the treatment of infertility associated with insulin resistance (male obesity, polycystic ovary syndrome).

Keywords: AMPK, testis, ovary, germ cells, fertility

\section{Introduction}

The 5' AMP-activated protein kinase (AMPK) is a serine/threonine heterotrimeric kinase composed of one catalytic $\alpha$-subunit bound with $\beta$ - and $\gamma$-regulatory subunits. The genes encoding the three subunits of AMPK are highly conserved in eukaryotic species including vertebrates, invertebrates, plants, fungi, and protozoa (Hardie et al., 2003; Ghillebert et al., 2011). Activation of AMPK occurs with the phosphorylation of the $\alpha$-subunit at Threonine 172. AMPK is sensitive to the AMP to ATP ratio and is activated by an increasing AMP concentration and by the upstream kinases including liver kinase B1 (LKB1) and calcium/calmodulin (CaM) kinase (CaMKK) (Woods et al., 2003; Hawley et al., 2005). It can also be dephosphorylated by phosphatases [Protein kinase phosphatase-1 and -2A (PP2A and PP2C)] (Lu et al., 2010; Joseph et al., 2015). AMPK is activated in pathophysiological situations (exercise, stress), by metabolic hormones (leptin, adiponectin, ghrelin) or pharmacological agents [5-aminoimidazole-4-carboxamide-1- $\beta$-D-riboside (AICAR), metformin and thiazolidinediones (TZD)] (Hardie, 2015). It regulates energy homeostasis by maintaining constant intracellular ATP concentrations by stimulation of catabolic pathways and inhibition of anabolic pathways (Hardie, 2015). Several studies have also shown that AMPK is expressed in gonads (Tosca et al., 2005; Dupont et al., 2012; Tartarin et al., 2012a) and could play a key role in the reproductive function in linking the gonadal axis with energy balance. More precisely, AMPK is present in ovarian (granulosa and theca cells, oocytes and corpora lutea) and testicular (Sertoli, leydig and germinal cells) cells in different species [oyster (Guévelou et al., 2013), 
C. elegans (Lee et al., 2008), bird (Tosca et al., 2006a; Nguyen et al., 2014), mammals: cow (Tosca et al., 2007a), pig (Mayes et al., 2007), rodents (Tosca et al., 2005; Downs et al., 2010; Tartarin et al., 2012a) and human (Pellatt et al., 2011)]. This kinase controls gonad steroidogenesis and germinal cell maturation but also cell proliferation and survival, polarity, formation, and maintenance of cellular junctional complexes, and cytoskeletal dynamics. In this review we report briefly some of the known functions of AMPK in the female and male gonad, and then we describe the potential role of this kinase in the interactions between metabolism and gonadal function. Most of the studies and conclusions are based on animal studies. However, we reported human studies (about granulosa and thecal cells or human embryonic testis) when it was possible.

\section{Gonadal Steroidogenesis}

In female mammals and birds, the role of AMPK has been studied in detail in granulosa cell cultures by using pharmacological agents and adenovirus-mediated expression of dominant negative forms of AMPK (Tosca et al., 2005). AMPK activators inhibit the secretion of progesterone and/or estradiol by granulosa cells in mammals (Tosca et al., 2005, 2007a). In rat and bovine species, this inhibition is associated with a decrease in 3beta-hydroxysteroid dehydrogenase ( $3 \beta$-HSD) mRNA and protein levels and a decrease in MAP kinase (MAPK) extracellular signal-regulated kinases (ERK) 1/2 phosphorylation (Tosca et al., 2005, 2007a, 2010). In rats, AMPK activation induced by metformin does not reduce aromatase expression and estradiol production. However, it decreases progesterone synthesis and the expression of different proteins involved in steroidogenesis [ $3 \beta$-HSD, cytochrome P450 (CYP11A1), steroidogenic acute regulatory protein (StAR)] (Tosca et al., 2006b). Metformin reduces follicle-stimulating hormone (FSH) but not forskolin-stimulated aromatase expression and activity in an AMP-activated protein kinase-independent manner in a human granulosa cell line (Rice et al., 2013). Also in human granulosa cells, metformin decreases androgen synthesis, by directly inhibiting cytochrome P450 17alpha-hydroxylase (Cyp17) activity (La Marca et al., 2000). In contrast, it has been shown that AMPK could improve androgen production by adrenal cells (Hirsch et al., 2012). Even if no studies have shown a role of AMPK in ovarian steroidogenesis in vivo, this has been largely demonstrated in vitro.

A total $\alpha 1$ AMPK knock out mouse model has been developed (Tartarin et al., 2012a). The male $\alpha 1 \mathrm{AMPK}^{-/-}$have high levels of testosterone that are not due to adrenal disorders or to glucorticoid resistance but to hyperactive Leydig cells (Tartarin et al., 2012a). Indeed, the Leydig cells of these animals have an increased volume, an altered endoplasmic reticulum area, a high intratesticular cholesterol concentration and a greater expression of proteins involved in steroid production (Tartarin et al., 2012a). These data accord with those described previously in vitro in granulosa cells but also in Leydig cells in response to a modulation of AMPK activity either pharmacologically or genetically. Certainly in MA-10 and MLTC-1 Leydig cells, AMPK activation inhibits cAMP-induced steroidogenesis by repressing the expression of key regulators of steroidogenesis, including the cholesterol carrier, StAR and the nuclear receptor Nr4al (Abdou et al., 2014). In the latter study, the authors suggest that some AMPK-sensitive element(s) containing sites for nuclear receptors of NR4A1 are located in the StAR promoter and are required for elevated cAMP dependent activation (Abdou et al., 2014). This suggests that activation of AMPK reduce the activity of NR4A1 and StAR expression. Furthermore, in primary rat Leydig cells, resveratrol, an AMPK agonist impairs human chorionic gonadotropin (hCG)-mediated testosterone production by repressing StAR expression (Svechnikov et al., 2009). In humans, the association of increased steroid production and the inhibition of AMPK could be associated to the PeutzJeghers Syndrome (PJS) (Ham et al., 2013). Peutz-Jeghers syndrome is an autosomal-dominant disorder that arises as a consequence of mutations in the serine/threonine kinase 11 (STK11) gene that encodes LKB1. In these PJS patients, excess estrogen and an increase in testicular aromatase expression is associated with a decrease in AMPK phosphorylation in the testis (Ham et al., 2013). Thus, AMPK could be a molecular modulator that inhibits gonadal steroidogenesis to preserve cellular energy homeostasis and prevent excess steroid production.

An important study for human health found that when human and mouse fetal testes were cultured in the presence of metformin, there was a reduction in testosterone secretion and mRNA of key factors which are involved in steroidogenesis (Tartarin et al., 2012b). This was also associated with an increase in lactate production. Furthermore, in vivo administration of metformin during pregnancy reduced the testicular size of fetal and neonatal testes. Although the number of germ cells was not altered by metformin treatment, the number of Sertoli cells was reduced in both fetal and neonatal testes. Interestingly the androgen producing Leydig cell population was only reduced in the fetal period at 16 days post-coitum (Tartarin et al., 2012b). This study presented a potentially harmful effect of metformin treatment on the development of fetal testes (Tartarin et al., 2012b). These effects were likely to result from a metforminstimulated AMPK-mediated reduction in cellular proliferation (Kayampilly and Menon, 2012), indicating that the reduction in steroidogenesis occurred as a result of reduced testicular growth.

\section{Proliferation and Survival of Somatic Gonadal Cells}

Gonadal somatic cells comprise the granulosa, cumulus and theca cells of the ovary, and the Sertoli and Leydig cells of the testis. Proliferation and survival of somatic cells are indispensable for fertility. Indeed, it is well known that proliferating granulosa cells support the progression of follicular growth and oocyte maturation. In males, testis size and sperm production are directly correlated to the total number of adult Sertoli cells. Regulation of proliferation and survival processes involves different hormones including FSH. As AMPK has previously been described as inhibiting proliferation of somatic cells (Tosca et al., 2010; Hardie, 2011; Kayampilly and Menon, 2012; Riera 
et al., 2012), we will examine the proliferative role of AMPK for these critical cell types.

In C. elegans, AMPK promotes survival and arrests germline development during nutrient stress (Fukuyama et al., 2012). More precisely, AMPK $\alpha 1$ and AMPK $\alpha 2$ (aak-1 and aak2 ), the two catalytic $\alpha$ subunits of AMP-activated protein kinase, regulate germline quiescence by suppressing activity of target of rapamycin complex 1 (TORC1) that is involved in cell growth, cell proliferation, cell motility, cell survival, protein synthesis, and transcription. Similarly in rat Sertoli cells, Riera et al. (2012) observed that activation of AMPK induces a decrease in FSH-stimulated Sertoli cell proliferation through a phosphatidylinositol 3-kinase (PI3K)/protein kinase $\mathrm{B}$ (Akt)/mTORC1 mechanisms but also an increase in cyclin dependent kinase inhibitor (CDKI, p19INK4d, p21Cip1, and p27Kip1) expression (Riera et al., 2012). In agreement with these data, Tosca et al. (2010) observed that metformin-induced AMPK activation reduces cell growth, protein synthesis and MAPK ERK1/2 and ribosomal protein S6 kinase (p90rsk) phosphorylation in response to insulin-like growth factor 1 (IGF1) in cultured bovine granulosa cells. Furthermore, Kayampilly and Menon observed that exposure of rat granulosa cells with a pharmacological activator of AMPK increased p27kip expression, an inhibitor of the cell cycle (Kayampilly and Menon, 2009). These latter authors have also observed that activation of AMPK induced by dihydrotestosterone (DHT) treatment decreases granulosa cell mitogenesis and consequently could contribute to ovulatory dysfunction observed in hyperandrogenic states (Kayampilly and Menon, 2012).

\section{Maturation of Germ Cells}

\section{The Oocyte}

The role of AMPK in mammalian oocyte maturation is strikingly species specific. AMPK improves resumption of oocyte meiosis in mice (Chen et al., 2006; Downs and Chen, 2006; Larosa and Downs, 2007; Chen and Downs, 2008) but not in rats (Downs, 2011) and pharmacological activation of AMPK blocks nuclear oocyte maturation in pigs and cattle (Mayes et al., 2007; Tosca et al., 2007b; Santiquet et al., 2014). The oocyte is reliant on the metabolism of lactate and pyruvate from the tricarboxylic acid cycle (TCA cycle) and oxidative phosphorylation for most of its energy stores (Biggers et al., 1967; Leese and Barton, 1984; Roberts et al., 2002). In human granulosa cells, AMPK could be also involved in lactate production which is important for follicular development (Richardson et al., 2009). The cumulus-oocyte complex (COC) also metabolizes glucose via numerous important pathways such as the pentose phosphate pathway and glycolysis. These metabolic pathways are critical for successful oocyte maturation and resumption of meiosis (Downs and Mastropolo, 1994; Downs et al., 1996; Sutton et al., 2003a,b). Cyclic adenosine monophosphate (cAMP), synthesized by adenylate cyclase downstream of the pentose phosphate pathway, is an important negative regulator of meiotic maturation. It is well known that degradation of cAMP by phosphodiestrases triggers resumption of meiosis. The depletion of cAMP results in an increase in the AMP/ATP ratio. As AMP levels rise, AMPK is triggered and activates a number of enzymes involved in energy producing pathways and inhibiting energy consuming pathways (Downs et al., 2002). This makes AMPK critically important for oocyte developmental competence.

In mouse oocytes, the $\alpha 1 \mathrm{AMPK}$ subunit is more abundant than $\alpha 2 A M P K$. Immunolocalization of the $\alpha 1$ catalytic subunit of AMPK showed an association with condensed chromatin and the meiotic spindle but not in the spindle poles or midbody. In the absence of $\alpha 1 \mathrm{AMPK}$ specifically in the oocyte, a decrease in $\mathrm{mdm} 2$ protein level, a strong negative regulator of $\mathrm{p} 53$, leads to an increase in the p53 content and probably induces cell cycle arrest as shown by the few number of oocyte fertilized in IVF or by the lower litter size in comparison to control mice (Bertoldo et al., 2014b, 2015). AMPK activation increases the rate of germinal vesicle breakdown (GVBD), spindle formation and polar body (PB) extrusion whereas the kinase has no effect on peripheral movement of the spindle. The meiosis-inducing actions and localization of AMPK are regulated by microtubule spindle integrity during mouse oocyte maturation (Ya and Downs, 2014). Interestingly, in mice, fatty acid oxidation is required for AMPKinduced maturation in vitro (Vasangkar and Downs, 2013).

The AMPK activator, AICAR, is a potent stimulator of maturation in mouse cumulus cell-enclosed oocytes (CEO) and denuded oocytes (DO), but only marginally stimulatory in rat CEO and ineffective in rat DO (Downs, 2011). AICAR and compound $\mathrm{C}$ produced contrasting results on polar body formation in cultured CEO in rat and mouse. Active AMPK was colocalized with chromatin after GVBD in rat and mouse oocytes, but did not appear at the spindle poles in rat oocytes as it did in mouse oocytes. These data highlight significant differences in meiotic regulation between the two species (Downs, 2011).

Contrary to results obtained with mouse oocytes, bovine and porcine oocyte meiosis is inhibited by activators of AMPK which is activated by AMP, the degradation product of cAMP (Bilodeau-Goeseels et al., 2007; Mayes et al., 2007; BilodeauGoeseels, 2011). During oocyte in vitro maturation (IVM), Santiquet et al. (2014) cultured porcine oocytes in the presence of AICAR and assessed the oocytes response in reference to oocyte nuclear maturation and cumulus cell expansion. Nuclear maturation was inhibited, however, this effect was only observed in cumulus enclosed oocytes, suggesting that cumulus cells are essential for AICAR's effect on oocyte maturation. In addition, AICAR inhibited cumulus expansion, which normally occurs in response to $\mathrm{FSH}$ and/or epidermal growth factor (EGF) during IVM (Harper and Brackett, 1993; Lonergan et al., 1996; Ritter et al., 2015). The results in porcine are supported by those in bovine where supplementation of metformin during embryo in vitro production resulted in AMPK mediated activation of TSC2 (Pikiou et al., 2015) and probably a reduction in TOR complex signaling and protein synthesis inhibition. In bovine COCs, metformin blocks meiotic progression at the germinal vesicle stage, activates AMPK, and inhibits MAPK3/1 phosphorylation in both the oocytes and cumulus cells during in vitro maturation. Moreover, cumulus cells were essential for the effects of metformin on bovine oocyte maturation, whereas MAPK ERK1/2 phosphorylation was not (Tosca et al., 2007b). While the precise targets of AMPK in the COCs are not entirely 
known, AMPK has been shown to modulate protein synthesis in various cell types (Hormon et al., 2002; Proud, 2004) and proteins involved in communication with somatic cells (see next section).

As observed in the large animal species, AMPK signaling keeps nemertean oocytes from maturing (Stricker et al., 2013). Unlike in mice, where the onset of oocyte maturation (germinal vesicle breakdown, GVBD) is blocked by cAMP and triggered by AMPK, oocytes of the marine nemertean worm Cerebratulus undergo GVBD in response to cAMP elevations and AMPK deactivation (Stricker, 2011). In addition these effects are observed only in the absence of the surrounding somatic cells (Stricker et al., 2010). These results also provide evidence for a novel GVBD-regulating mechanism involving AMPK deactivation by cAMP-mediated S485/491 phosphorylation and further highlight the highly species specific effects of AMPK in regard to oocyte maturation.

\section{Male Germ Cells}

$\alpha$ AMPK is present in male germ cells of oyster (Guévelou et al., 2013), chicken (Nguyen et al., 2014) and mammals (Hurtado de Llera et al., 2012a; Tartarin et al., 2012a; Cordova et al., 2014). In oyster, it is more highly expressed in male gonad than in female and its expression is more important during the first stage of gametogenesis when germ cells proliferate (Guévelou et al., 2013).

To traverse the female reproductive tract, it is essential that mammalian spermatozoa acquire the functional competence to achieve this objective in order to successfully fertilize the oocyte. These functional markers include motility, capacitation, hyperactivation and the acrosome reaction (Hurtado de Llera et al., 2015). It was recently demonstrated that AMPK protein is highly expressed in ejaculated boar and chicken spermatozoa (Hurtado de Llera et al., 2012a; Nguyen et al., 2014), and in mouse epididymal sperm (Tartarin et al., 2012a; Bertoldo et al., 2014a) and that it localizes in the head of the spermatozoon and in the midpiece of the flagellum (Hurtado de Llera et al., 2013). In the boar, pharmacological inhibition of AMPK lead to a reduction in motility (Hurtado de Llera et al., 2012a) while concomitantly causing changes in mitochondrial membrane potential, sperm plasma membrane fluidity and organization and acrosome integrity (Hurtado de Llera et al., 2013; Martin-Hidago et al., 2013). Similar results have been described in the chicken. These studies highlight the conservation of the AMPK function in sperm activity.

Interestingly, Hurtado de Llera et al. noted that the majority of studies to date that had studied sperm physiology as a function of AMPK had only done so under conditions where AMPK was inhibited (Hurtado de Llera et al., 2012b, 2015) or was genetically silenced (Tartarin et al., 2012a). Consequently they conducted a study to assess sperm physiology while activating AMPK indirectly. They observed under extended periods $(24 \mathrm{~h})$ of AMPK activation, boar spermatozoa had reduced motility, acrosome membrane integrity and organization and fluidity of the plasma membrane which was associated with an increase in lipid disorganization (Hurtado de Llera et al., 2015). As these processes are critical under the different environmental conditions experienced by spermatozoa when transiting through the female reproductive tract to accomplish fertilization, it becomes obvious from studies carried out so far that an optimal level of AMPK activation is essential for regulating spermatozoa function (Hurtado de Llera et al., 2015).

Nakada et al. demonstrated that spermatogenesis is intimately linked to mitochondrial respiration (Nakada et al., 2006), and recently Pellicione et al. associated asthenozoospermia with abnormal mitochondrial ultrastructure (Pelliccione et al., 2011). Therefore, it is likely that the motility disturbances observed in our $\alpha 1$ AMPK KO model and in the LKB1 KO model that presented with abnormalities in spermatozoa functionality and morphology (motility and head morphology) (Towler et al., 2008; Tartarin et al., 2012a), was directly linked to mitochondrial dysgenesis. Similarly, incubation of sperm from boar with an AMPK inhibitor, compound $\mathrm{C}$, lead to a reduction in motility (Martin-Hidago et al., 2013). Surprisingly, a mouse model inactivated for an oxidative stress sensor protein like glutathione peroxydase 4 (Liang et al., 2009; Schneider et al., 2009) is described with structural abnormalities in spermatozoa analogous to those observed in $\alpha 1 \mathrm{AMPK} \mathrm{KO}$, suggesting that mitochondria dysfunction could affect oxidative stress oxidative status.

Diabetic and infertile men present with a decrease in antioxidant concentrations and an increase in ROS generation in their semen, even before cryopreservation, demonstrating that the sperm from this group are at increased risk of oxidative damage (Lewis et al., 1995; Garcez et al., 2010). Several studies have demonstrated that metformin can reduce the levels of oxidative DNA damage and afford anti-oxidant protection (Attia et al., 2009; Onken and Driscoll, 2010; Martin-Montalvo et al., 2013). Metformin has been shown to guard against diabetesinduced genomic instability in sperm cells and the bone marrow of diabetic rats (Attia et al., 2009), so we can hypothesize that the use of metformin in diabetic patients would have no negative effect in the integrity of spermatozoa. However, we cannot exclude consequences on the paternal genome for oocyte fertilization. For example, treatment of murine sperm with high concentration of metformin increased histone deacetylase activity (Bertoldo et al., 2014a). Curiously, treatment of sperm with known natural activators of AMPK such as resveratrol or a synthetic activator like metformin, present positive effects such as reduction in DNA damage and lipid peroxidation (Bertoldo et al., 2014a). A study in the wood frog (Rana sylvatica), a species with a high freeze tolerance, has revealed that AMPK was more activated in liver and muscle tissue, thus presenting AMPK as a molecule with cryoprotective properties (Rider et al., 2006). Subsequently modification of AMPK has been exploited in the freezing protocols of mammalian semen (Bertoldo et al., 2014a; Cordova et al., 2014). Metformin was used in mouse semen extender (Bertoldo et al., 2014a) and following thawing, spermatozoa showed an improvement in fertilization capability in vitro. This was associated with a reduction in the number of abnormal zygotes following IVF when mouse spermatozoa was frozen in the presence of metformin compared to controls (Bertoldo et al., 2014a). AMPK was also modulated in stallion semen extender where there was an improvement in sperm quality post-thaw (Cordova et al., 2014). As the reports of AMPK 
presence in spermatozoa are growing in number, we believe it is reasonable to assume that AMPK activity is likely required for optimal mammalian spermatozoa physiology.

\section{Germinal and Somatic Cells Interactions}

\section{Cumulus-oocyte Complex}

Gap junction communication between cumulus cells and oocytes is crucial for oocyte meiotic maturation and to acquire full developmental competence (Gilchrist et al., 2004; Gilchrist, 2011; Li and Albertini, 2013). Such that maintenance of gap junction communication and delayed meiotic resumption have been shown to increase oocyte developmental competence (Thomas et al., 2004; Gharibi et al., 2013). Gap junction communication between the oocyte and the surrounding cumulus cells is established by the formation of bidirectional channels. The connexins family, which compose gap junctions is involved in oocyte/cumulus cell communication and allows passage of ions and small organic molecules. Loss of connexin 37 and connexin 43 in mouse oocytes or cumulus cells impaired fertility through inhibiting oocyte growth and folliculogenesis (Winterhager and Kidder, 2015). Electron microscopic analysis has shown that junctions between granulosa cells and oocytes are altered or absent as in connexin $37^{-/-}$mice (Simon et al., 1997). In the mouse, deletion of $\alpha 1 \mathrm{AMPK}$ specifically in the oocyte lead to a reduction in connexin 37 between the oocyte and cumulus cells at the Metaphase II stage which was associated with reduced fertility following IVF, and suggests a reduction in gap junction communication (Bertoldo et al., 2015). Reductions in connexin 26 and connexin 37 expression were also described in a diabetic mouse model, where oocyte quality is poor (Ratchford et al., 2008). In an non-mammalian example, Alesutan et al., demonstrated that active AMPK decreased connexin 26 abundance in the cell membrane in xenopus oocytes (Alesutan et al., 2011), suggesting disparate regulation of gap junction communication by AMPK between species.

Deletion of $\alpha 1 \mathrm{AMPK}$ in oocytes leads to reductions in other proteins associated with intercellular communication within the cumulus oocyte complexes (Bertoldo et al., 2015). These include $\mathrm{N}$-cadeherin and $\beta$-catenin (markers for adherens junctions) and occludin (a marker for tight junctions) (Bertoldo et al., 2015). The cumulus-oocyte complex interacts with granulosa cells through adhesion junctions composed of proteins such as E-cadherin and N-cadherin (Rufas et al., 2000; Machell and Farookhi, 2003). Expression of $\mathrm{N}$-cadherin for example, increases throughout maturation, fertilization and early embryogenesis (Ziv et al., 2002), and N-cadherin mediated cell contact is associated with the maintenance of meiotic arrest (Peluso, 2006). Deregulation of these proteins impacts oocyte maturation, fertilization and early embryogenesis (Ziv et al., 2002; Peluso, 2006).

Furthermore in the bovine, it was recently demonstrated that the transzonal processes (TZP) that traverse the zona pellucida transfer RNA molecules from cumulus cells to the oocyte (Macaulay et al., 2014). It was proposed that these TZPs are held in place by adherens like junctions (Macaulay et al., 2014) and are critical for oocyte developmental competence. During repair of lung capillary endothelium $\alpha 1 \mathrm{AMPK}$ promotes the development of intercellular adherens junctions by binding with $\mathrm{N}$-cadherin and contributes to repair (Creighton et al., 2011). This supports the notion that AMPK may have a critical role in oocyte developmental competence by maintaining open oocyte-somatic cell communication channels through at least gap, adherens and tight junctions. Taken together the literature supports the concept that AMPK plays a crucial role in maintaining metabolic and molecular intercellular coupling between the oocyte and its somatic cells and breakdown of this coupling results in reduced oocyte developmental competence.

\section{Blood Testis Barrier}

As in the cumulus oocyte complex, male germ cells are closely linked their support cells; the Sertoli cells during their maturation. Sertoli cells have an important role in the shaping of the spermatid head for example (Kierszenbaum and Tres, 2004). Different transgenic mouse models show that AMPK plays a role in intra-testicular communication. Absence of the upstream AMPK kinase, LKB1 reduced mature spermatozoa production associated with abnormal acrosome morphology and a defect in Sertoli cell polarity and testicular junctional complexes (Towler et al., 2008). Patients with Peutz-Jeghers syndrome present a similar phenotype with alteration of sperm production associated with modifications of tight junctions in the blood-testis-barrier (Ulbright et al., 2007; Chen et al., 2012; Tanwar et al., 2012). The disruption of the $\alpha 1 A M P K$ gene in the whole murine testis induced altered sperm morphology without presenting abnormalities in Sertoli cell nucleus polarization (Tartarin et al., 2012a). Nonetheless, transmission electron microscopy analyses have shown the presence of some disrupted Sertoli cell/elongated spermatid germ cell junctions (Tartarin et al., 2012a). Interestingly, a similar phenotype in sperm head or midpiece morphology has been already described in mice deleted for adhesion molecules like nectin-2 (Mueller et al., 2003) or Tslc1 (Surace et al., 2006). The fact that absence of the $\alpha 1 A M P K$ gene lead to a mild phenotype in contrast to LKB1 could be explained by the activation of LKB1 through several other AMPK-related kinases present in the testis such as microtubule-associated protein/microtubule affinity-regulating kinases (MARK2) (Bessone et al., 1999) or SNRK (Jaleel et al., 2005) as a compensatory mechanism. This hypothesis is supported by the decrease in phosphorylation of MARK in testis in LKB1-KO mice (Kojima et al., 2007; Tanwar et al., 2012). The reduction and/or incorrect relocalization of markers of adherens junctions ( $\beta$-catenin and N-Cadherin) (Kopera et al., 2010) and tight junctions (occludin and ZO-1) (Kopera et al., 2010) in Sertoli cells from LKB1-KO mice suggests a loss of contact with germ cells leading probably to alteration in germ cell shape (Kleymenova et al., 2005). Notably, altered $\beta$-catenin expression has previously been described to compromise Sertoli cell function and the maturation of germ cells and lead to infertility (Lee et al., 2005; Tanwar et al., 2010; Kerr et al., 2013).

The use of the AMPK activator (AICAR) can also influence junction complex integrity in rat Sertoli cells as has been described by Galardo et al. (2010). Rat Sertoli cells incubated with AICAR stabilized ZO-1 protein as observed by immunofluorescence (Galardo et al., 2010). The use of EGTA to 
limit the free calcium concentration in culture medium induced a redistribution of ZO-1 between Sertoli cells. Addition of AICAR or adenosine, in the presence of EGTA permitted the rescue of ZO-1 distribution to normal conditions at the cell membranes (Galardo et al., 2010). As in oocytes, the cAMP/PKA pathway is modified in the absence of $\alpha 1 \mathrm{AMPK}$ in Sertoli cells, raising the question about the interaction between AMPK/cAMP signaling and the functionality of the blood-testis barrier permeability. Indeed, the cAMP signal has been described to be involved for the formation and maturation of male germ cells (Scobey et al., 2001), and can perturb junctions in rat Sertoli cells (Lui and Lee, 2005).

\section{Interface between AMPK and Modification of Metabolism}

Diet restriction is well known to promote longevity and reduce fertility in several species like C. elegans, drosophila melanogaster, birds and mammals. Diet restriction induces a negative energy balance which activates some energy sensors such as AMPK and the sirtuins which promote respiration and energy production by mitochondria. In mice, a deficiency in LKB1 or AMPK in mature Sertoli cells negatively impacts mitochondrial function, and has been associated with loss of quiescence and an activation of cell proliferation (Bertoldo et al., 2013). The association between nutrient availability, mitochondrial function and fertility has been already observed in invertebrates. In C. elegans the germinal stem cells regulate longevity through the TOR pathway (Arrantes-Oliveira et al., 2002), and similarly in drosophila TOR signaling is involved in the regulation of female germinal stem cell proliferation as a function of the availability of nutrients (Drummond-Barbosa and Spradling, 2001; Lafever and Drummond-Barbosa, 2005; Lafever et al., 2010; Shyh-Chang et al., 2013). These results are also observed in Sertoli cells where stimulation with an AMPK activator such as metformin or AICAR has consequences on lactate production and the increase in glucose transport (Galardo et al., 2007). One hypothesis of the action of metformin, is an indirect effect: an inhibition of the respiratory chain in mitochondria leading to an increase in lactate production, and in the AMP: ATP ratio inducing the activation of AMPK. On the other hand, the inactivation of $\alpha 1 \mathrm{AMPK}$ in Sertoli cells, reduces the expression of mitochondrial markers (cytochrome c and PGC1a) and the ATP content, and increases the lactate production (Bertoldo et al., 2013). The increase in lactate, in this case, could be due to a switch in the cell between energy production by respiration to the aerobic glycolysis. Thus, $\alpha 1 \mathrm{AMPK}$ deficiency enhances the Warburg Effect which can be associated with increased cell proliferation in vitro (Faubert et al., 2013). In addition, glycolysis could increase the allocation of glucose carbon into lipids and explain the increase in lipid vesicles. We cannot exclude that a modification in lipid metabolism in Sertoli cells has a consequence on germ cells. Indeed, some studies have described lipid transport from the Sertoli cells to the germ cells (Saether et al., 2003). Moreover, several recent studies using mice deficient in genes related to lipid metabolism, have described that the accumulation of excess lipid droplets in Sertoli cells resulted in impaired spermatogenesis (Coussens et al., 2008). Therefore, a balance of lipid metabolism in Sertoli cells is essential for normal spermatogenesis (Selva et al., 2004).

Ratchford et al. have hypothesized that abnormalities in oocyte metabolism, such as that observed in diabetes, could potentially preprogramme the oocyte for unfavorable outcomes after fertilization (Ratchford et al., 2007). Furthermore, Wang et al. (2009) concluded that maternal diabetes results in numerous oocyte deficiencies. Glucose metabolism is essential for successful oocyte maturation and the recommencement of meiosis (Downs and Mastropolo, 1994). It is well known that mitochondria can influence the developmental competence of the oocyte (Thouas et al., 2004). Certainly mitochondria play a key role in cellular energy generation, the control of cell death (Perez et al., 2000) and the dynamic process of meiosis including DNA reorganization (Wang et al., 2009). In the case of diabetes, mitochondria are abnormally distributed around the spindle or in the oocyte cytoplasm (Wang et al., 2009). Ratchford et al. observed that under hyperglycaemic conditions, phosphorylated ACC, a downstream target of AMPK and phosphorylated AMPK were both decreased in diabetic oocytes, demonstrating decreased AMPK activity (Ratchford et al., 2007). Diabetic oocytes were also metabolically perturbed leading to altered AMPK activity. Interestingly, increasing AMPK with AICAR in these oocytes during the preovulatory phase corrected the metabolic and meiotic perturbations observed. For these crucial activities in oocyte maturation, mitochondrial redistribution, activity or dysfunction have been suggested as markers of oocyte quality and are strongly related to fertilization rates and embryo development (Van Blerkom, 2004; Wang et al., 2009).

During the last decade a variety of natural ligands and synthetic ligands have been shown to activate AMPK including resveratrol (Baur et al., 2006), sulforaphane (Choi et al., 2014), niacin (Thirunavukkarasu et al., 2006), berberine (Brusg et al., 2006), metformin (Zhou et al., 2001), and thiazolidinediones (Fryer et al., 2002). Some of these compounds have nonlinear dose-response characteristics, such as that of hormesis and have the ability to inhibit the mitochondrial complex I at elevated concentrations that mimick diet restriction (Gems and Partridge, 2008). The hypothesis of hormesis lends weight to differences in phenotype associated with differences of metformin concentration. High metformin concentrations (approximately $5 \mathrm{mM}$ ) is enough to inhibit the respiratory chain complex 1 in mitochondria leading to an increase in the AMP/ATP ratio (El-Mir et al., 2000; Owen et al., 2000) and different metformin concentrations induce increases in oxidant defenses as well as an extension of lifespan (Onken and Driscoll, 2010; Martin-Montalvo et al., 2013). The difference in species sensitivity has been already observed as mouse tissue is 10 fold less sensitive than human tissue (Tartarin et al., 2012b).

Metformin is a good example for mimicking diet restriction, because in mouse liver, metformin has been shown to induce a similar transcription pattern to diet restriction especially (Dhahbi et al., 2005). However, similar effects have been described in C. elegans where metformin administration increases the 
lifespan and produces several diet restriction-like phenotypes such as reduction in fecundity and a decrease in fat storage in animals which are fed ad-libitum (Onken and Driscoll, 2010). In drosophila, metformin exposure for 7 days at 25 and $50 \mathrm{mM}$ concentration increases significantly the number of eggs laid in contrast to untreated controls. But after 14 days of treatment, egglaying in females on $25 \mathrm{mM}$ metformin was similar to controls and at $50 \mathrm{mM}$ of metformin the females laid significantly fewer eggs (Onken and Driscoll, 2010). Interestingly in flies, metformin targets AMPK and inhibits the TOR pathway (Kalender et al., 2010; Slack et al., 2012). From the reports to date, we can conclude that effects on fertility (increases or reductions in the number of egg laid depending the time and concentration of metformin treatment) remains partially understood and controversial (He and Wondisford, 2015).

SIRT1 is widely regarded as a critical regulator of energy homeostasis and is implicated in a wide variety of cellular processes including metabolic diseases, cancer, aging, and reproduction (Bordone and Guarente, 2005; Brooks and $\mathrm{Gu}$, 2009; Haigis and Sinclair, 2010). Furthermore it is known to interact with AMPK (Fulco et al., 2008; Narala et al., 2008; Canto and Auwerx, 2009). We have recently provided evidence in the oocyte that $\alpha 1 \mathrm{AMPK}$ could be involved in chromatin remodeling, because we observed an increase in acetylation of $\mathrm{H} 3$ histone in oocytes from $\alpha 1 \mathrm{AMPK}$ knockout oocytes (Bertoldo et al., 2015). This was correlated, as expected with a reduction in histone deacetylase SIRT1 expression in vivo. In vitro Sirt1 has the ability to deacetylate histone substrates in a $\mathrm{NAD}^{+}$-dependent manner (Vaquero et al., 2004b) and hyperacetylation occurs when SIRT1 is knocked down (Vaquero et al., 2004b). Male mice deficient in SIRT1 present with altered germ cell maturation and increased DNA damage in germ cells (Coussens et al., 2008). Together, these data suggest that AMPK can modify oocyte proteins and histone acetylation status. These observations could

\section{References}

Abdou, H. S., Bergeron, F., and Tremblay, J. J. (2014). A cell-autonomous molecular cascade initiated by AMP-activated protein kinase represses steroidogenesis. Mol. Cell. Biol. 34, 4257-4271. doi: 10.1128/MCB.00734-14

Akiyama, T., Nagata, M., and Aoki, F. (2006). Inadequate histone deacetylation during oocyte meiosis causes aneauploidy and embryo death in mice. Proc. Natl. Acad. Sci. U.S.A. 103, 7339-7344. doi: 10.1073/pnas.0510946103

Alesutan, I., Sopjani, M., Munoz, C., Fraser, S., Kemp, B. E., Foller, M., et al. (2011). Inhibition of connexin 26 by the AMP-activated protein kinase. J. Membr. Biol. 240, 151-158. doi: 10.1007/s00232-011-9353-y

Arrantes-Oliveira, N., Apfeld, J., Dillin, A., and Kenyon, C. (2002). Regulation of life-span by germ-lne stem cells in Caenorhabditis elegans. Science 295, 502-505. doi: 10.1126/science.1065768

Attia, S. M., Helal, G. K., and Alhaider, A. A. (2009). Assessment of genomic instability in mormal and diabetic rats treated with metformin. Chem. Biol. Interact. 180, 296-304. doi: 10.1016/j.cbi.2009.03.001

Baur, J. A., Pearson, K. J., Price, N. L., Jamieson, H. A., Lerin, C., Prabhu, V. V., et al. (2006). Resveratrol improves health and survival of mice on a high-calorie diet. Nature 444, 337-342. doi: 10.1038/nature05354

Bendale, D. S., Karpe, P. A., Chhabra, R., Shete, S. P., Shah, H., and Tikoo, K. (2013). 17- $\beta$ Estradiol prevents cardiovascular dysfunction in postmenopausal metabolic syndrome by involving SIRT1/AMPK/H3 acetylation. Br. J. Pharmacol. 170, 779-795. doi: 10.1111/bph.12290 be linked to other reports such as those relating to the aorta and heart tissue where a decrease in AMPK and SIRT1 expression is associated with increased H3 acetylation (Bendale et al., 2013). Interestingly, acetylation of histones $\mathrm{H} 3$ and $\mathrm{H} 4$ appear to be linked to an overexpression of connexin 43 in a prostate cell line (Ogawa et al., 2005; Hernandez et al., 2006), and PGC1 $\alpha$ and p53 can modify their accessibility (Vaquero et al., 2004a; Wakeling et al., 2009; Nelson et al., 2012), possibly suggesting some level of control of intercellular communication and apoptosis. Interestingly, inadequate histone deacetylation causes changes in gene expression, which can lead to embryopathy in mice (Akiyama et al., 2006).

\section{Conclusion}

The involvement of AMPK in fertility control is conserved throughout several animal species from the oyster, C. elegans, drosophila, birds and mammals. Its expression is present in different compartments of the ovary and testis and through the different stages of maturation of germ cells, germline stem cells to oocytes and spermatozoa. Apart from its classical functions on metabolism, proliferation and antiinflammatory effects observed in the gonad, AMPK is also able to modulate steroidogenesis, and to impact morphology and normal nuclear maturation of germ cells though interaction of germ cells with their nurse somatic cells. Some mechanisms elucidated are directly linked with mitochondrial function and junctional proteins. Despite the possibility of different sub-unit combinations of AMPK, absence of only $\alpha 1 \mathrm{AMPK}$ leads to moderate failure of fertility in both sexes.

\section{Funding}

This review was financially supported by ANR "Fertinergy grant.”

Bertoldo, M. J., Guibert, E., Faure, M., Rame, C., Foretz, M., Viollet, B., et al. (2015). Specific deletion of AMP-activated protein kinase ( $\alpha 1 \mathrm{AMPK}$ ) in murine oocytes alters junctional protein expression and mitochindrial physiology. PLoS ONE 10:e0119680 doi: 10.1371/journal.pone.0119680

Bertoldo, M. J., Guibert, E., Tartarin, P., Guillory, V., and Froment, P. (2014a). Effect of metformin on the fertilizing ability of mouse spermatozoa. Cryobiology 68, 262-268. doi: 10.1016/j.cryobiol.2014.02.006

Bertoldo, M. J., Guibert, E., Tartarin, P., Guillou, F., Foretz, M., Viollet, B., et al. (2013). L'AMPK, une protéine impliquée dans les interactions entre les cellules nourricières et les cellules germinales. Ann. Endocrinol. 74, 266. doi: 10.1016/j.ando.2013.07.097

Bertoldo, M. J., Locatelli, Y., O'neill, C., and Mermillod, P. (2014b). Impacts of and interactions between environmental stress and epigenetic programming during early embryo development. Reprod. Fertil. Dev. doi: 10.1071/RD14049. [Epub ahead of print].

Bessone, S., Vidal, F., Le Bouc, Y., Epelbaum, J., Bluet-Pajot, M. T., and Darmon, M. (1999). EMK protein kinase-null mice: dwarfism and hypofertility associated with alterations in the somatotrope and prolactin pathways. Dev. Biol. 214, 87-101. doi: 10.1006/dbio.1999.9379

Biggers, J. D., Whittingham, D. G., and Donahue, R. P. (1967). The pattern of energy metabolism in the mouse oocyte and zygote. Proc. Natl. Acad. Sci. U.S.A. 58, 560-567. doi: 10.1073/pnas.58.2.560

Bilodeau-Goeseels, S. (2011). Cows are not mice: the role of cyclic AMP, phosphodiesterases, and adenosine monophosphate-activated protein kinase 
in the maintenance of meiotic arrest in bovine oocytes. Mol. Reprod. Dev. 78, 734-743. doi: 10.1002/mrd.21337

Bilodeau-Goeseels, S., Sasseville, M., Guillemette, C., and Richard, F. J. (2007). Effects of adenosine monophosphate-activated kinase activators on bovine oocyte nuclear maturation in vitro. Mol. Reprod. Dev. 74, 1021-1034. doi: $10.1002 / \mathrm{mrd} .20574$

Bordone, L., and Guarente, L. (2005). Calorie restriction, SIRT1 and metabolism: understanding longevity. Nat. Rev. Mol. Cell Biol. 6, 298-305. doi: $10.1038 / \mathrm{nrm} 1616$

Brooks, C. L., and Gu, W. (2009). How does SIRT1 affect metabolism, senescence and cancer? Nat. Rev. Cancer 9, 123-128. doi: 10.1038/n rc2562

Brusg, J. M., Ancellin, N., Grondin, P., Guillard, R., Martin, S., Saintillan, Y., et al. (2006). Inhibition of lipid synthesis through activation of AMP kinase: an additional mechanism for the hypolipidemic effects of berberine. J. Lipid Res. 47, 1281-1288. doi: 10.1194/jlr.M600020-JLR200

Canto, C., and Auwerx, J. (2009). PGC-1alpha, SIRT1 and AMPK, an energy sensing network that controls energy expenditure. Curr. Opin. Lipidol. 20, 98-105. doi: 10.1097/MOL.0b013e328328d0a4

Chen, H., Ruan, Y. C., Xu, W. M., Chen, J., and Chan, H. C. (2012). Regulation of male fertility by CFTR and implications in male infertility. Hum. Reprod. Update 18, 703-713. doi: 10.1093/humupd/dms027

Chen, J., and Downs, S. M. (2008). AMP-activated protein kinase is involved in hormone-induced mouse oocyte meiotic maturation in vitro. Dev. Biol. 313, 47-57. doi: 10.1016/j.ydbio.2007.09.043

Chen, J., Hudson, E., Chi, M. M., Chang, A. S., Moley, K. H., Hardie, D. G., et al. (2006). AMPK regulation of mouse oocyte meiotic resumption in vitro. Dev. Biol. 291, 227-238. doi: 10.1016/j.ydbio.2005.11.039

Choi, K. M., Lee, Y. S., Kim, W., Kim, S. J., Shin, K. O., Yu, J. Y., et al. (2014). Sulforaphane attenuates obesity by inhibiting adipogenesis and activating the AMPK pathway in obese mice. J. Nutr. Biochem. 25, 201-207. doi: 10.1016/j.jnutbio.2013.10.007

Cordova, A., Strobel, P., Vallejo, A., Valenzuela, P., Ulloa, O., Burgoa, R. A., et al. (2014). Use of hypometabolic TRIS extenders and high cooling rate refrigeration for cryopreservation of stallion sperm: presence and sensitivity of 5' AMP-activated protein kinase (AMPK). Cryobiology 69, 473-481. doi: 10.1016/j.cryobiol.2014.10.008

Coussens, M., Maresh, J. G., Yanagimachi, R., Maeda, G., and Allsopp, R. (2008). Sirtl deficiency attenuates spermatogenesis and germ cell function. PLOS ONE 3:e1571. doi: 10.1371/journal.pone.0001571

Creighton, J., Jian, M., Sayner, S., Alexeyev, M., and Insel, P. A. (2011). Adenosine monophosphate-activated kinase alphal promotes endothelial barrier repair. FASEB J. 25, 3356-3365. doi: 10.1096/fj.10-179218

Dhahbi, J. M., Mote, P. L., Fahy, G. M., and Spindler, S. R. (2005). Identification of potential caloric restriction mimetics by mircroarray profiling. Physiol. Genomics 23, 343-350. doi: 10.1152/physiolgenomics.00069.2005

Downs, S. M. (2011). Mouse versus rat: profound differences in meiotic regulation at the level of the isolated oocyte. Mol. Reprod. Dev. 78, 778-794. doi: $10.1002 / \mathrm{mrd} .21377$

Downs, S. M., and Chen, J. (2006). Induction of meiotic maturation in mouse oocytes by adenosine analogs. Mol. Reprod. Dev. 73, 1159-1168. doi: $10.1002 / \mathrm{mrd} .20439$

Downs, S. M., Hudson, E. R., and Hardie, D. G. (2002). A potential role for AMPactivated protein kinase in meiotic induction in mouse oocytes. Dev. Biol. 245, 200-212. doi: 10.1006/dbio.2002.0613

Downs, S. M., Humpherson, P. G., Martin, K. L., and Leese, H. J. (1996). Glucose utilization during gonadotropin-induced meiotic maturation in cumulus-cell enclosed mouse oocytes. Mol. Reprod. Dev. 44, 121-131.

Downs, S. M., and Mastropolo, A. M. (1994). The participation of energy substrates in the control og meiotic maturation in murine oocytes. Dev. Biol. 162, 154-168. doi: 10.1006/dbio.1994.1075

Downs, S. M., Ya, R., and Davis, C. C. (2010). Role of AMPK throughout meiotic maturation in the mouse oocyte: evidence for promotion of polar body formation and suppression of premature activation. Mol. Reprod. Dev. 77, 888-899. doi: 10.1002/mrd.21229

Drummond-Barbosa, D., and Spradling, A. C. (2001). Stem cells and their progeny respond to nutritional changes during Drosophila oogenesis. Dev. Biol. 231, 265-278. doi: 10.1006/dbio.2000.0135
Dupont, J., Reverchon, M., Cloix, L., Froment, P., and Rame, C. (2012). Involvement of adipokines, AMPK, PI3K and the PPAR signaling pathways in ovarian follicle development and cancer. Int. J. Dev. Biol. 56, 959-967. doi: 10.1387/ijdb.120134jd

El-Mir, M. Y., Nogueira, V., Fontaine, E., Averet, N., Rigoulet, M., and Leverve, X. (2000). Dimethylbiguanide inhibits cell respiration via an indirect effect targeted on the respiratory chain complex I. J. Biol. Chem. 275, 223-228. doi: $10.1074 /$ jbc.275.1.223

Faubert, B., Boily, G., Izreig, S., Griss, T., Samborska, B., Dong, Z., et al. (2013). AMPK is a negative regulator of the Warburg effect and suppresses tumor growth in vivo. Cell Metab. 17, 113-124. doi: 10.1016/j.cmet.2012.12.001

Fryer, L. G., Parbu-Patel, A., and Carling, D. (2002). The Anti-diabetic drugs rosiglitazone and metformin stimulate AMP-activated protein kinase through distinct signaling pathways. J. Biol. Chem. 277, 25226-25232. doi: 10.1074/jbc.M202489200

Fukuyama, M., Sakuma, K., Park, R., Kasuga, H., Nagaya, R., Atsumi, Y., et al. (2012). C. elegans AMPKs promote survival and arrest germline development during nutrient stress. Biol. Open 1, 929-936. doi: 10.1242/bio.2012836

Fulco, M., Cen, Y., Zhao, P., Hoffman, E. P., McBurney, M. W., Sauve, A. A., et al. (2008). Glucose restriction inhibits skeletal myoblast differentiation by activating SIRT1 through AMPK-mediated regulation of Nampt. Dev. Cell 14, 661-673. doi: 10.1016/j.devcel.2008.02.004

Galardo, M. N., Riera, M. F., Pellizzari, E. H., Cigorraga, S. B., and Meroni, S. B. (2007). The AMP-activated protein kinase activator, 5-aminoimidazole-4carboxamide-1-b-D-ribonucleoside, regulates lactate production in rat Sertoli cells. J. Mol. Endocrinol. 39, 279-288. doi: 10.1677/JME-07-0054

Galardo, M. N., Riera, M. F., Pellizzari, E. H., Sobarzo, C., Scarcelli, R., Denduchis, B., et al. (2010). Adenosine regulates Sertoli cell function by activating AMPK. Mol. Cell. Endocrinol. 330, 49-58. doi: 10.1016/j.mce.2010.08.007

Garcez, M. E., dos Santos Branco, C., Lara, L. V., Pasqualotto, F. F., and Salvador, M. (2010). Effects of resveratrol supplementation on cryopreservation medium of human semen. Fertil. Steril. 94, 2118-2121. doi: 10.1016/j.fertnstert.2010.01.058

Gems, D., and Partridge, L. (2008). Stress-response hormesis and aging: "that which does not kill us makes us stronger." Cell Metab. 7, 200-203. doi: 10.1016/j.cmet.2008.01.001

Gharibi, S. H., Hajian, M., Ostadhosseini, S., Forouzanfar, M., and Nasr-Esfahani, M. H. (2013). Effect of phosphodiesterase type 3 inhibitor on nuclear maturation and in vitro development of ovine oocytes. Theriogenology 80, 302-312. doi: 10.1016/j.theriogenology.2013.04.012

Ghillebert, R., Swinnen, E., Wen, J., Vandesteene, L., Ramon, M., Norga, K., et al. (2011). The AMPK/SNF1/SnRK1 fuel gauge and energy regulator: structure, function and regulation. FEBS J. 278, 3978-3990. doi: 10.1111/j.17424658.2011.08315.x

Gilchrist, R. B. (2011). Recent insights into oocyte-follicle cell interactions provide opportunities for the development of new approaches to in vitro maturation. Reprod. Fertil. Dev. 23, 23-31. doi: 10.1071/RD10225

Gilchrist, R. B., Ritter, L. J., and Arsmstrong, D. T. (2004). Oocyte-somatic cell interactions during follicle development in mammals. Anim. Reprod. Sci. 82-83, 431-446. doi: 10.1016/j.anireprosci.2004.05.017

Guévelou, E., Huvet, A., Galindo-Sanchez, C. E., Milan, M., Quillien, V., Daniel, J.-Y., et al. (2013). Sex-specific regulation of AMP-activated protein kinase (AMP) in the Pacific Oyster Crassostrea gigas. Biol. Reprod. 89, 1-15. doi: 10.1095/biolreprod.113.109728

Haigis, M. C., and Sinclair, D. A. (2010). Mammalian sirtuins: biological insights and disease relevance. Annu. Rev. Pathol. 5, 253-295. doi: 10.1146/annurev.pathol.4.110807.092250

Ham, S., Meachem, S. J., Choong, C. S., Charles, A. K., Baynam, G. S., Jones, T. W., et al. (2013). Overexpression of aromatase associated with loss of heterozygosity of the STK11 gene accounts for prepubertal gynecomastia in boys with Peutz-Jeghers syndrome. J. Clin. Endocrinol. Metab. 98, E1979-E1987. doi: $10.1210 /$ jc. $2013-2291$

Hardie, D. G. (2011). AMP-activated protein kinase: an energy sensor that regulates all aspects of cell function. Genes Dev. 25, 1895-1908. doi: $10.1101 / \operatorname{gad} .17420111$

Hardie, D. G. (2015). AMPK: positive and negative regulation, and its role in whole-body energy homeostasis. Curr. Opin. Cell Biol. 33, 1-7. doi: 10.1016/j.ceb.2014.09.004 
Hardie, D. G., Scott, J. W., Pan, D. A., and Hudson, E. R. (2003). Management of cellular energy by the AMP-activated protein kinase system. FEBS Lett. 546, 113-120. doi: 10.1016/S0014-5793(03)00560-X

Harper, K. M., and Brackett, B. G. (1993). Bovine blastocyst development after in vitro maturation in a defined medium with epidermal growth factor and low concentrations of gonadotropins. Biol. Reprod. 48, 409-416. doi: 10.1095/biolreprod48.2.409

Hawley, S. A., Pan, D. A., Musatrd, K. J., Ross, L., Bain, J., Edelman, A. M., et al. (2005). Calmodulin-dependent protein kinase kinase-beta is an alternative upstrream kinase for AMP-activated protein kinase. Cell Metab. 2, 9-19. doi: 10.1016/j.cmet.2005.05.009

He, L., and Wondisford, F. E. (2015). Metformin: concentrations matter. Cell Metab. 21, 159-162. doi: 10.1016/j.cmet.2015.01.003

Hernandez, M., Shao, Q., Yang, X. J., Luh, S. P., Kandouz, M., Batist, G., et al. (2006). A histone deacetylation-dependent mechanism for transcriptional repression of the gap junction gene cx43 in prostate cancer cells. Prostate 66, 1151-1161. doi: 10.1002/pros.20451

Hirsch, A., Hahn, D., Kempna, P., Hofer, G., Mullis, P. E., Nuoffer, J. M., et al. (2012). Role of AMP-activated protein kinase on steroid hormone biosynthesis in adrenal NCI-H295R cells. PLoS ONE 7:e30956. doi: 10.1371/journal.pone.0030956

Hormon, S., Browne, G., Krause, U., Patel, J., Vertommen, D., Bertrand, L., et al. (2002). Activation of AMP-activated protein kinase leads to the phosphorylation of elongation factor 2 and an inhibition of protein synthesis. Curr. Biol. 12, 1419-1423. doi: 10.1016/S0960-9822(02)01077-1

Hurtado de Llera, A., Martin-Hidago, D., Gil, M. C., Garcia-Marin, L. J., and Bragado, M. J. (2012a). AMP-activated kinase AMPK is expressed in boar spermatozoa and regulates motility. PLoS ONE 7:e38840. doi: 10.1371/journal.pone.0038840

Hurtado de Llera, A., Martin-Hidago, D., Gil, M. C., Garcia-Marin, L. J., and Bragado, M. J. (2012b). The AMPK activator metformin inhibits one of the main functions of boar spermatozoa, motility. FEBS J. 279(Suppl. 1), $52-576$.

Hurtado de Llera, A., Martin-Hidago, D., Rodriguez-Gil, J. E., Gil, M. C., GarciaMarin, L. J., and Bragado, M. J. (2013). AMP-activated kinase, AMPK, is involved in the maintenance of plasma membrane organization in boar. Biochim. Biophys. Acta 1928, 2143-2151. doi: 10.1016/j.bbamem.2013.05.026

Hurtado de Llera, A., Martin-Hidalgo, D., Gil, M. C., Garcia-Marin, L. J., and Bragado, M. J. (2015). AMPK up-activation reduces motility and regulates other functions of boar spermatozoa. Mol. Hum. Reprod. 21, 31-45. doi: 10.1093/molehr/gau091

Jaleel, M., McBride, A., Lizcano, J. M., Deak, M., Toth, R., Morrice, N. A., et al. (2005). Identification of the sucrose non-fermenting realted kinase SNRK, as a novel LKB1 substrate. FEBS Lett. 579, 1417-1423. doi: 10.1016/j.febslet.2005.01.042

Joseph, B. K., Liu, H. Y., Francisco, J., Pandya, D., Donigan, M., Gallo-Ebert, C., et al. (2015). Inhibition of AMP kinase by the protein phosphatase 2A heterotrimer, PP2APpp2r2d. J. Biol. Chem. 290, 10588-10598. doi: 10.1074/jbc.M114.626259

Kalender, A., Selvaraj, A., Gulati, P., Brule, S., Viollet, B., Kemp, B. E., et al. (2010). Metformin, independent of AMPK, inhibits mTORC1 in a rag GTPasedependent manner. Cell Metab. 11, 390-401. doi: 10.1016/j.cmet.2010.03.014

Kayampilly, P. P., and Menon, K. M. (2009). Follicle-stimulating hormone inhibits adenosine 5'-monophosphate-activated protein kinase activation and promotes cell proliferation of primary granulosa cells in culture through an Aktdependent pathway. Endocrinology 150, 929-935. doi: 10.1210/en.2008-1032

Kayampilly, P. P., and Menon, K. M. (2012). AMPK activation by dihydrotestosterone reduces FSH-stimulated cell proliferation in rat granulosa cells by inhibiting ERK signaling pathway. Endocrinology 153, 2831-2838. doi: 10.1210/en.2011-1967

Kerr, G. E., Young, J. C., Horvay, K., Abud, H. E., and Loveland, K. L. (2013). Regulated Wnt/Beta-catenin signaling sustains adult spermatogenesis in mice. Biol. Reprod. 90:3. doi: 10.1095/biolreprod.112.105809

Kierszenbaum, A. L., and Tres, L. L. (2004). The acrosome-acroplaxomemanchette complex and the shaping of the spermatid head. Arch. Histol. Cytol. 67, 271-284. doi: 10.1679/aohc.67.271

Kleymenova, E., Swanson, C., Boekelheide, K., and Gaido, K. W. (2005). Exposure in utero to $\operatorname{di}(n$-butyl) phthalate alters the vimentin cytoskeleton of fetal rat Sertoli cells and disrupts Sertoli cell-gonocyte contact. Biol. Reprod. 73, 482-490. doi: 10.1095/biolreprod.104.037184

Kojima, Y., Miyoshi, H., Clevers, H. C., Oshima, M., Aoki, M., and Taketo, M. M. (2007). Suppression of tubulin polymerization by the LKB1-microtubuleassociated protein/microtubule affinity-regulating kinase signaling. J. Biol. Chem. 282, 23532-23540. doi: 10.1074/jbc.M700590200

Kopera, I. A., Bilinska, B., Cheng, C. Y., and Mruk, D. D. (2010). Sertoli-germ cell junctions in the testis: a review of recent data. Philos. Trans. R. Soc. Lond. B Biol. Sci. 365, 1593-15605. doi: 10.1098/rstb.2009.0251

Lafever, L., and Drummond-Barbosa, D. (2005). Direct control of germline stem cell division and cyst growth by neural insulin in Drosophila. Science 309, 1071-1073. doi: 10.1126/science. 1111410

Lafever, L., Feokitistov, A., Hsu, H. J., and Drummond-Barbosa, D. (2010). Specific roles of target of rapmycin in the control of stem cells and their progeny in the Drosophila ovary. Development 137, 2117-2126. doi: 10.1242/dev.050351

La Marca, A., Eqbe, T. O., Morqante, G., Paglia, T., Cianci, A., and De Leo, V. (2000). Metformin treatment reduces ovarian cytochrome P-450c17alpha response to human chorionic gonadotrophin in women with insulin resistance-related polycystic ovary syndrome. Hum. Reprod. 15, 21-23. doi: 10.1093/humrep/15.1.21

Larosa, C., and Downs, S. M. (2007). Meiotic inductionb by heat stress in mouse oocytes: involvement of AMP-activated protein kinase and MAPK family members. Biol. Reprod. 76, 476-486. doi: 10.1095/biolreprod.106.057422

Lee, H., Cho, J. S., Lambacher, N., Lee, J., Lee, S. J., Lee, T. H., et al. (2008). The Caenorhabditis elegans AMP-activated protein kinase AAK-2 is phosphorylated by LKB1 and is required for resistance to oxidative stress and for normal motility and foraging behavior. J. Biol. Chem. 283, 14988-14993. doi: 10.1074/jbc.M709115200

Lee, N. P. Y., Mruk, D., Wong, C., and Cheng, C. Y. (2005). Regulation of Sertoli-Germ cell adherens junction dynamics in the testis via the nitric oxide synthase (NOS)/cGMP/protein kinase G (PRKG)/ $\beta$-catenin (CATNB) signaling pathway: an in vitro and in vivo study. Biol. Reprod. $73,458-471$. doi: 10.1095/biolreprod.105.040766

Leese, H. J., and Barton, A. M. (1984). Pyruvate and glucose uptake by mouse ova and preimplantation embryos. J. Reprod. Fertil. 72, 9-13. doi: 10.1530/jrf.0.0720009

Lewis, S. E., Boyle, P. M., McKinney, K. A., Young, I. S., and Thompson, W. (1995) Total antioxidant capacity of seminal plasma is different in fertile and infertile men. Fertil. Steril. 64, 868-870.

Li, R., and Albertini, D. F. (2013). The road to maturation: somatic cell interaction and self-organization of the mammalian oocyte. Nat. Rev. Mol. Cell Biol. 14, 141-152. doi: 10.1038/nrm3531

Liang, H., Yoo, S. E., Na, R., Walter, C. A., Richardson, A., and Ran, Q. (2009). Short form glutathione peroxidase 4 is the essential isoform required for survival and somatic mitochondrial functions. J. Biol. Chem. 284, 30836-30844. doi: 10.1074/jbc.M109.032839

Lonergan, P., Carolan, C., Van Langendonckt, A., Donnay, I., Khatir, H., and Mermillod, P. (1996). Role of epidermal growth factor in bovine oocyte maturation and preimplantation embryo development in vitro. Biol. Reprod. 54, 1420-1429. doi: 10.1095/biolreprod54.6.1420

Lu, J., Wu, D. M., Zheng, Y. L., Hu, B., Zhang, Z. F., Shan, Q., et al. (2010). Quercetin activates AMP-activated protein kinase by reducing PP2C expression protecting old mouse brain against high cholesterol-induced neurotoxicity. J. Pathol. 222, 199-212. doi: 10.1002/path.2754

Lui, W. Y., and Lee, W. M. (2005). cAMP perturbs inter-Sertoli tight junction permeability barrier in vitro via its effect on proteasome-sensitive ubiquitination of occludin. J. Cell. Physiol. 203, 564-572. doi: 10.1002/jcp.20254

Macaulay, A. D., Gilbert, I., Caballero, J., Barreto, R., Fournier, E., Tossou, P., et al. (2014). The gametic synapse: RNA transfer to the bovine oocyte. Biol. Reprod. 91, 90. doi: 10.1095/biolreprod.114.119867

Machell, N. H., and Farookhi, R. (2003). E- and N-cadherin expression and distribution during luteinization in the rat ovary. Reproduction 125, 791-800. doi: $10.1530 /$ rep. 0.1250791

Martin-Hidago, D., Hurtado de Llera, A., Yeste, M., Cruz Gil, M., Bragado, M. J., and Garcia-Marin, L. J. (2013). Adenosine monophosphate-activated kinase, AMPK, is involved in the maintenance of the quality of extended boar semen during long-term storage. Theriogenology 80, 285-294. doi: 10.1016/j.theriogenology.2013.02.015 
Martin-Montalvo, A., Mercken, E. M., Mitchell, S. J., Palacios, H. H., Mote, P. L., Scheibye-Knudsen, M., et al. (2013). Metformin improves healthspan and lifespan in mice. Nat. Commun. 4:2192. doi: 10.1038/ncomms3192

Mayes, M. A., Laforest, M. F., Guillemette, C., Gilchrist, R. B., and Richard, F. J. (2007). Adenosine 5'-monophosphate kinase-activated protein kinase (PRKA) activators delay meiotic resumption in porcine oocytes. Biol. Reprod. 76, 589-597. doi: 10.1095/biolreprod.106.057828

Mueller, S., Rosenquist, T. A., Takai, Y., Bronson, R. A., and Wimmer, E. (2003). Loss of nectin-2 at Sertoli-spermatid junctions leads to male infertility and correlates with severe spermatozoan head and midpiece malformation, impaired binding to the zona pellucida, and oocyte penetration. Biol. Reprod. 69, 1330-1340. doi: 10.1095/biolreprod.102.014670

Nakada, K., Sato, A., Yoshida, K., Morita, T., Tanaka, H., Inoue, S., et al. (2006). Mitochondria-related male infertility. Proc. Natl. Acad. Sci. U.S.A. 103, 15148-15153. doi: 10.1073/pnas.0604641103

Narala, S. R., Allsopp, R. C., Wells, T. B., Zhang, G., Prasad, P., Coussens, M. J., et al. (2008). SIRT1 acts as a nutrient-sensitive growth suppressor and its loss is associated with increased AMPK and telomerase activity. Mol. Biol. Cell 19, 1210-1219. doi: 10.1091/mbc.E07-09-0965

Nelson, L. E., Valentine, R. J., Cacicedo, J. M., Gauthier, M.-S., Ido, Y., and Ruderman, N. B. (2012). A novel inverse relationship between metformintriggered AMPK-SIRT1 signaling and p53 protein abundance in high glucoseexposed HepG2 cells. Am. J. Physiol. Cell Physiol. 303, C4-C13. doi: 10.1152/ajpcell.00296.2011

Nguyen, T. M. D., Alves, S., Grasseau, I., Metayer-Coustard, S., Praud, C., Froment, P., et al. (2014). Central role of 5'-AMP-activated protein kinase in chicken sperm functions. Biol. Reprod. 91, 1-15. doi: 10.1095/biolreprod.114. 121855

Ogawa, T., Hayashi, T., Tokunou, M., Nakachi, K., Trosko, J. E., Chang, C. C., et al. (2005). Suberoylanilide hydroxamic acid enhances gap junctional intercellular communication via acetylation of histone containing connexin 43 gene locus. Cancer Res. 65, 9771-9778. doi: 10.1158/0008-5472.CAN-05-0227

Onken, B., and Driscoll, M. (2010). Metformin induces a dietary restriction-like state and oxidative stress response to extend C. elegans healthspan via AMPK, LKB1, and SKN-1. PLoS ONE 5:e8758. doi: 10.1371/journal.pone.0008758

Owen, M. R., Doran, E., and Halestrap, A. P. (2000). Evidence that metformin exerts its anti-diabetic effects through inhibition of complex 1 of the mitochondrial respiratory chain. Biochem. J. 348, 607-614. doi: 10.1042/02646021:3480607

Pellatt, L. J., Rice, S., and Mason, H. D. (2011). Phosphorylation and activation of AMP-activated protein kinase (AMPK) by metformin in the human ovary requires insulin. Endocrinology 152, 1112-1118. doi: 10.1210/en.2009-1429

Pelliccione, F., Micillo, A., Cordeschi, G., D’angeli, A., Necozione, S., Gandini, L., et al. (2011). Altered ultrastructure of mitochondrial membranes is strongly associated with unexplained asthenozoospermia. Fertil. Steril. 95, 641-646. doi: 10.1016/j.fertnstert.2010.07.1086

Peluso, J. J. (2006). N-cadherin mediated cell contact inhibits germinal vesicle brakdown in mouse oocytes maintained in vitro. Reproduction 131, 429-437. doi: 10.1530/rep.1.00863

Perez, G. I., Trbovich, A. M., Gosden, R. G., and Tilly, J. L. (2000). Mitochondria and the death of oocytes. Nature 403, 500-501. doi: 10.1038/35000651

Pikiou, O., Vasilaki, A., Leondaritis, G., Vamvakopoulos, N., and Messinis, I. E. (2015). Effects of metformin of fertilisation of bovine oocytes and early embryo development: possible involvement of AMPK3-mediated TSC2 activation. Zygote 23, 58-67. doi: 10.1017/S0967199413000300

Proud, C. G. (2004). Role of mTOR signalling in the control of translation initiation and elongation of nutrients. Curr. Top. Microbiol. Immunol. 279, 215-244. doi: 10.1007/978-3-642-18930-2_13

Ratchford, A. M., Chang, A. S., Chi, M. M.-Y., Sheridan, R., and Moley, K. H. (2007). Maternal diabetes adversely affects AMP-activated protein kinase activity and cellular metabolism in murine oocytes. Am. J. Physiol. Endocrinol. Metab. 293, E1198-E1206. doi: 10.1152/ajpendo.00097.2007

Ratchford, A. M., Esguerra, C. R., and Moley, K. H. (2008). Decreased oocytegranulosa cell gap junction communication and connexin expression in a Type 1 diabetic mouse model. Mol. Endocrinol. 22, 2643-2654. doi: 10.1210/me.2007-0495

Rice, S., Elia, S., Jawad, Z., Pellatt, L., and Mason, H. D. (2013). Metformin inhibits follicle-stimulating hormone (FSH) action in human granulosa cell: relevance to polycystic ovary syndrome. J. Clin. Endocrinol. Metab. 98, E1491-E1500. doi: 10.1210/jc.2013-1865

Richardson, M. C., Ingamells, S., Simonis, C. D., Cameron, I. T., Sreekumar, R., Vijendren, A., et al. (2009). Stimulation of lactate production in human granulosa cells by metformin and potential involvement of adenosine 5' monophosphate-activated protein kinase. J. Clin. Endocrinol. Metab. 94, 670-677. doi: 10.1210/jc.2008-2025

Rider, M. H., Hussain, N., Horman, S., Dilworth, S. M., and Storey, K. B. (2006). Stress-induced activation of the AMP-activated protein kinase in the freeze tolerant frog Rana sylvatica. Cryobiology 53, 297-309. doi: 10.1016/j.cryobiol.2006.08.001

Riera, M. F., Regueira, M., Galardo, M. N., Pellizzari, E. H., Meroni, S. B., and Cigorraga, S. B. (2012). Signal transduction pathways in FSH regulation of rat Sertoli cell proliferation. Am. J. Physiol. Endocrinol. Metab. 302, E914-E923. doi: 10.1152/ajpendo.00477.2011

Ritter, L. J., Sugimura, S., and Gilchrist, R. B. (2015). Oocyte induction of EGF responsiveness in somatic cells is associated with the acquisition of porcine oocyte developmental competence. Endocrinology 156, 2299-2312. doi: 10.1210/en.2014-1884

Roberts, R., Franks, S., and Hardy, K. (2002). Culture environment modulates maturation and metabolism of human oocytes. Hum. Reprod. 17, 2950-2956. doi: 10.1093/humrep/17.11.2950

Rufas, O., Fisch, B., Ziv, S., and Shalgi, R. (2000). Expression of cadherin adhesion molecules on human gametes. Mol. Hum. Reprod. 6, 163-169. doi: 10.1093/molehr/6.2.163

Saether, T., Tran, T. N., Rootwelt, H., Christophersen, B. O., and Haugen, T. B. (2003). Expression and regulation of delta5-desaturase, delta6-desaturase, stearoyl-coenzyme A (CoA) desaturase 1, and stearoyl-CoA desaturase 2 in rat testis. Biol. Reprod. 69, 117-124. doi: 10.1095/biolreprod.102. 014035

Santiquet, N., Sasseville, M., Laforest, M., Guillemette, C., Gilchrist, R. B., and Richard, F. J. (2014). Activation of $5^{\prime}$ adenosine monophosphate-activated protein kinase blocks cumulus cell expansion through inhibition of protein synthesis during in vitro maturation in swine. Biol. Reprod. 91, 1-12. doi: 10.1095/biolreprod.113.116764

Schneider, M., Forster, H., Boersma, A., Seiler, A., Wehnes, H., Sinowatz F., et al. (2009). Mitochondrial glutathione peroxidase 4 disruption causes male infertility. FASEB J. 23, 3233-3242. doi: 10.1096/fj.09132795

Scobey, M. J., Bertera, S., Somers, J. P., Watkins, S. C., Zeleznik, A. J., and Walker, W. H. (2001). Delivery of a cylic adenosine $3^{\prime}, 5^{\prime}$-monophosphate response element-binding protein (CREB) mutant to seminiferous tubules results in impaired spermatogenesis. Endocrinology 142, 948-954. doi: 10.1210/endo.142.2.7948

Selva, D. M., Hirsch-Reinshagen, V., Burgess, B., Zhou, S., Chan, J., McIsaac, S., et al. (2004). The ATP-binding cassette transporter 1 mediates lipid efflux from Sertoli cells and influences male fertility. J. Lipid Res. 45, 1040-1050. doi: 10.1194/jlr.M400007-JLR200

Shyh-Chang, N., Daley, G. Q., and Cantley, L. C. (2013). Stem cell metabolism in tissue development and aging. Development 140, 2535-2547. doi: 10.1242/dev.091777

Simon, A. M., Goodenough, D. A., Li, E., and Paul, D. L. (1997). Female fertility in mice lacking connexin 37. Nature 385, 525-529. doi: 10.1038/ $385525 \mathrm{a} 0$

Slack, C., Foley, A., and Partridge, L. (2012). Activation of AMPK by the putative dietary restriction mimetic metformin is insufficient to extend lifespan in Drosophila. PLoS ONE 7:e47699. doi: 10.1371/journal.pone.0047699

Stricker, S. A. (2011). Potential upstream regulators and downstream targets of AMP-activated kinase signaling during oocyte maturation in a marine worm. Reproduction 142, 29-39. doi: 10.1530/REP-10-0509

Stricker, S. A., Cline, C., and Goodrich, D. (2013). Oocyte maturation and fertilization in marine nemertean worms: using similar sorts of signaling pathways as in mammals, but often with differing results. Biol. Bull. 224, 137-155.

Stricker, S. A., Swiderek, L., and Nguyen, T. (2010). Stimulators of AMP-activated kinase (AMPK) inhibit seawater - but not cAMP-induced oocyte maturation in a marine worm: implications for interactions between cAMP and AMPK signaling. Mol. Reprod. Dev. 77, 497-510. doi: 10.1002/mrd.21177 
Surace, E. I., Strickland, A., Hess, R. A., Gutmann, D. H., and Naughton, C. K. (2006). Tslc1 (nectin-like molecule-2) is essential for spermatozoa motility and male fertility. J. Androl. 27, 816-825. doi: 10.2164/jandrol.106.000398

Sutton, M. L., Cetica, P. D., Beconi, M. T., Kind, M. L., Gilchrist, R. B., and Thompson, J. G. (2003a). Influence of oocyte-secreted factors and culture duration on the metabolic activity of bovine cumulus cell complexes. Reproduction 126, 27-43. doi: 10.1530/rep.0.1260027

Sutton, M. L., Gilchrist, R. B., and Thompson, J. G. (2003b). Effects of in-vivo and in-vitro environments on the metabolism of the cumulus-oocyte complex and its influence on oocyte developmental capacity. Hum. Reprod. Update 9, 35-48. doi: 10.1093/humupd/dmg009

Svechnikov, K., Spatafora, C., Svechnikova, I., Tringali, C., and Soder, O. (2009). Effects of resveratrol analogs on steroidogenesis and mitochondrial function in rat Leydig cells in vitro. J. Appl. Toxicol. 29, 673-680. doi: 10.1002/jat.1456

Tanwar, P. S., Kaneko-Tarui, T., Zhang, L., Rani, P., Taketo, M. M., and Teixeira, J. (2010). Constitutive WNT/Beta-catenin signaling in murine Sertoli cells disrupts their differentiation and ability to support spermatogenesis. Biol. Reprod. 82, 422-432. doi: 10.1095/biolreprod.109.079335

Tanwar, P. S., Kaneko-Tarui, T., Zhang, L., and Teixeira, J. M. (2012). Altered LKB1/AMPK/TSC1/TSC2/mTOR signaling causes disruption of Sertoli cell polarity and spermatogenesis. Hum. Mol. Genet. 21, 4394-4405. doi: $10.1093 / \mathrm{hmg} / \mathrm{dds} 272$

Tartarin, P., Guibert, E., Touré, A., Ouiste, C., Leclerc, J., Sanz, N., et al. (2012a). Inactivation of AMPK $\alpha 1$ induces asthenozoospermia and alters spermatozoa morphology. Endocrinology 153, 3468-3481. doi: 10.1210/en.2011-1911

Tartarin, P., Moison, D., Guibert, E., Dupont, J., Habert, R., Rouiller-Fabre, V., et al. (2012b). Metformin exposure affects human and mouse fetal testicular cells. Hum. Reprod. 27, 3304-3314. doi: 10.1093/humrep/des264

Thirunavukkarasu, M., Penumathsa, S., Juhasz, B., Zhan, L., Bagchi, M., Yasmin, T., et al. (2006). Enhanced cardiovascular function and energy level by a novel chromium (III)-supplement. Biofactors 27, 53-67. doi: 10.1002/biof.5520270106

Thomas, R. E., Armstrong, D. T., and Gilchrist, R. B. (2004). Bovine cumulus celloocyte gap junctional communication during in vitro maturation in response to manipulation of cell-specific cyclic adenosine $3^{\prime}, 5^{\prime}$-monophosophate levels. Biol. Reprod. 70, 548-556. doi: 10.1095/biolreprod.103.021204

Thouas, G. A., Trounson, A. O., Wolvetang, E. J., and Jones, G. M. (2004). Mitochondrial dysfunction in mouse oocytes results in preimplantation embryo arrest in vitro. Biol. Reprod. 71, 1936-1942. doi: 10.1095/biolreprod.104.033589

Tosca, L., Chabrolle, C., Uzbekova, S., and Dupont, J. (2007a). Effect of metformin on bovine granulosa cell steroidogenesis: possible involvement of adenosine 5' monophosphate-activated protein kinase (AMPK). Biol. Reprod. 76, 368-378. doi: 10.1095/biolreprod.106.055749

Tosca, L., Crochet, S., Ferré, P., Foufelle, F., Tesseraud, S., and Dupont, J. (2006a). AMP-activated protein kinase activation modulates progesterone secretion in granulosa cells from hen preovulatory follicles. J. Endocrinol. 190, 85-97. doi: 10.1677/joe.1.06828

Tosca, L., Froment, P., Solnais, P., Foufelle, F., and Dupont, J. (2005). Adenosine $5^{\prime}$-monophosphate-activated protein kinase regulates progesterone secretion in rat granulosa cells. Endocrinology 146, 4500-4513. doi: 10.1210/en.2005-0301

Tosca, L., Rame, C., Chabrolle, C., Tesseraud, S., and Dupont, J. (2010). Metformin decreases IGF1-induced cel proliferation and protein synthesis through AMPactivated protein kinase in cultured bovine granulosa cells Reproduction 139, 409-418. doi: 10.1530/REP-09-0351

Tosca, L., Solnais, P., Ferre, P., Foufelle, F., and Dupont, J. (2006b). Metformininduced stimulation of adenosine $5^{\prime}$ monophosphate-activated protein kinase (PRKA) impairs progesterone secretion in rat granulosa cells. Biol. Reprod. 75, 342-351. doi: 10.1095/biolreprod.106.050831
Tosca, L., Uzbekova, S., Chabrolle, C., and Dupont, J. (2007b). Possible role of $5^{\prime}$ AMP-activated protein kinase in the metformin-mediated arrest of bovine oocytes at the germinal vesicle stage during in vitro maturation. Biol. Reprod. 77, 452-465. doi: 10.1095/biolreprod.107.060848

Towler, M. C., Fogarty, S., Hawley, S. A., Pan, D. A., Martin, D. M., Morrice, N. A., et al. (2008). A novel short splice variant of the tumour suppressor LKB1 is required for spermiogenesis. Biochem. J. 416, 1-14. doi: 10.1042/BJ20081447

Ulbright, T. M., Amin, M. B., and Young, R. H. (2007). Intratubular large cell hyalinizing sertoli cell neoplasia of the testis: a report of 8 cases of a distinctive lesion of the Peutz-Jeghers syndrome. Am. J. Surg. Pathol. 31, 827-835. doi: 10.1097/PAS.0b013e3180309e33

Van Blerkom, J. (2004). Mitochondria in human oogenesis and preimplantation embryogenesis: engines of metabolism, ionic ergulation and developmental competence. Reproduction 128, 269-280. doi: 10.1530/rep.1.00240

Vaquero, A., Scher, M., Lee, D., Erdjument-Bromage, H., Tempst, P., and Reinberg, D. (2004a). Human SirT1 interacts with histone H1 and promotes formation of facultative heterochromatin. Mol. Cell 16, 93-105. doi: 10.1016/j.molcel.2004.08.031

Vaquero, A., Scher, M., Lee, D., Erdument-Bromage, H., Tempst, P., and Reinberg, D. (2004b). Human SirT1 interacts with histone H1 and promotes formation of facultative heterochromatin. Mol. Cell 16, 93-105. doi: 10.1016/j.molcel.2004.08.031

Vasangkar, D., and Downs, S. M. (2013). A requirement for fatty acid oxidation in the hormone-induced meiotic maturation of mouse oocytes. Biol. Reprod. 89, 43. doi: 10.1095/biolreprod.113.109058

Wakeling, L. A., Ions, L. J., and Ford, D. (2009). Could Sirt1-mediated epigenetic effects contribute to the longevity response to dietary restriction and be mimicked by other dietary interventions? Age 31, 327-341. doi: 10.1007/s11357-009-9104-5

Wang, Q., Ratchford, A. M., Chi, M. M.-Y., Schoeller, E., Frolova, A., Schedl, T., et al. (2009). Maternal diabetes causes mitochondrial dysfunction and meiotic defects in murine oocytes. Mol. Endocrinol. 23, 1603-1612. doi: 10.1210/me.2009-0033

Winterhager, E., and Kidder, G. M. (2015). Gap junction connexins in female reproductive organs: implications for women's reproductive health. Hum. Reprod. Update 21, 340-352. doi: 10.1093/humupd/dmv007

Woods, A., Johnstone, S. R., Dickerson, K., Leiper, F. C., Fryer, L. G., Neumann, D., et al. (2003). LKB1 is the upstream kinase in the AMP-activated protein kinase cascade. Curr. Biol. 13, 2004-2008. doi: 10.1016/j.cub.2003.10.031

Ya, R., and Downs, S. M. (2014). Perturbing microtubule integrity blocks AMP-activated protein kinase-induced meiotic resumption in cultured mouse oocytes. Zygote 22, 91-102. doi: 10.1017/S0967199412000457

Zhou, G., Myers, R., Li, Y., Chen, Y., Shen, X., Fenyk-Melody, J., et al. (2001). Role of AMP-activated protein kinase in mechanism of metformin action. J. Clin. Invest. 108, 1167-1174. doi: 10.1172/JCI13505

Ziv, S., Rufas, O., and Shalgi, R. (2002). Cadherin expression during gamete maturation and fertilzation in the rat. Mol. Reprod. Dev. 62, 547-556. doi: $10.1002 / \mathrm{mrd} .10149$

Conflict of Interest Statement: The authors declare that the research was conducted in the absence of any commercial or financial relationships that could be construed as a potential conflict of interest.

Copyright (c) 2015 Bertoldo, Faure, Dupont and Froment. This is an open-access article distributed under the terms of the Creative Commons Attribution License (CC $B Y)$. The use, distribution or reproduction in other forums is permitted, provided the original author(s) or licensor are credited and that the original publication in this journal is cited, in accordance with accepted academic practice. No use, distribution or reproduction is permitted which does not comply with these terms. 